\title{
Ductile damage evolution law for proportional and non-proportional loading conditions
}

\author{
Riccardo Fincato, Seiichiro Tsutsumi \\ University of Osaka, JWRI, Japan \\ fincato@jwri.osaka-u.ac.jp,tsutsumi@jwri.osaka-u.ac.jp \\ Hideto Momii \\ Nikken Engineering Corporation, Fukuoka, Japan \\ bideto.momii@nikkencorp.com
}

\begin{abstract}
The characterization of ductile damage evolution, and its description, have been the object of extensive research in the continuum damage mechanic field. Many different models have been developed since the pioneering works carried out a few decades ago. In detail, the stress triaxiality and the Lode angle parameters have been identified as the two main variables that affect the material ductility. The literature offers a great number of investigations under monotonic loading conditions, however, a proper characterization of the damage evolution under cyclic loading or nonproportional loading is still missing.

In this paper, an unconventional coupled elastoplastic and damage constitutive model with a Mohr-Coulomb failure criterion is presented. The novelty of this study is represented by the modification of the ductile damage law in order to consider the damage evolution under non-proportional loading conditions. Therefore, the idea is to investigate the structural response of a steel bridge column subjected to a cyclic non-proportional loading, showing how, a different approach in the description of the ductile damage evolution, is necessary for a realistic description of the pier behavior.
\end{abstract}

KEYwORDS. Ductile damage; Elastoplasticity; Non-proportional loading; Damage Subloading Surface model.

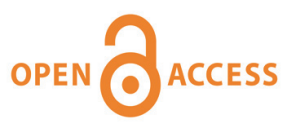

Citation: Fincato, R., Tsutsumi, S., Momii, H., Ductile damage evolution law for proportional and non-proportional loading conditions, Frattura ed Integrità Strutturale, 47 (2019) 231-246.

Received: 08.08 .2018

Accepted: 27.09.2018

Published: 01.01.2019

Copyright: (C) 2019 This is an open access article under the terms of the CC-BY 4.0, which permits unrestricted use, distribution, and reproduction in any medium, provided the original author and source are credited.

\section{INTRODUCTION}

$\mathrm{I}$ $\mathrm{n}$ the recent years, many authors tried to characterize the ductile behavior of metals by means of different types of numerical models (coupled elastoplastic and damage models, uncoupled models, phenomenological, etc.). The large campaign of experimental investigations carried out in the last decades (Algarni et al. [1]; Bai et al. [2]; Bao and Treitler 
[3]; Bao and Wierzbicki [4]; Brünig et al. [5]; Papasidero et al. [6]) pointed out that the stress triaxiality and the Lode angle are the main two factors that affect the ductility behavior in metals. In fact, monotonic loading tests, for different geometries and under different loading conditions (uniaxial extension, pure shear, plane strain, uniaxial compression), proved a different failure behavior for the same material. However, the literature still lacks a proper characterization of the damage evolution under non-proportional loading paths. In the recent years, Faleskog and Barsoum [7], Papasidero et al., Cortese et al. [8] and Algarni et al. [9] conducted a series of experiments aimed to identify the effect of the loading path on ductility. In detail, the work of Faleskog and Barsoum [7], Papasidero et al. [10] and Cortese et al. [8] consisted in the application of several non-proportional loading paths, as the result of the combination of tension-torsion or compression-torsion, on steel and aluminum tubular samples. On the other hand, Algarni et al. [9] tried to describe the crack formation on notched Iconel 718 bars in low cycle fatigue investigations. A common aspect that emerged from those previous works is that the deformation at fracture is higher when the load is proportional, suggesting that the damage accelerates whenever nonproportional loading conditions are triggered.

The present paper aims to investigate the influence of the loading path on the ductile damage evolution. The constitutive model Damage Subloading Surface (DSS) [11] was modified to account for an additional inelastic contribution, named tangential plasticity, that arises during the non-proportionality of the load. In detail, the numerical analyses focus the attention on the structural response of a steel bridge column subjected to various loading conditions. A modified MohrCoulomb criterion [12] is adopted for the description of the damage behavior of SS400 steel pier, with a modification of the damage evolution law.

The paper is organized as follows. A first section (i.e. theoretical framework) introduces the definition of proportional and nonproportional loadings. Subsequently, the main features of the DSS model are briefly described. Finally, the ductile damage criterion and a novel ductile damage evolution law are presented. The second section, numerical analyses, is divided into two parts. A simple numerical example shows the different damage evolution under proportional and non-proportional loading paths, clarifying the role of the tangential plasticity presented in the first section. The second part of the numerical analyses deals with a steel column that undergoes a cyclic non-proportional loading. The results will show the necessity of considering the tangential plasticity for a more realistic description of the structural response. The last section reports the concluding remarks of the paper, summarizing the theoretical approach and the advantages of the model.

\section{THEORETICAL FRAMEWORK}

7 he following section deals with the presentation of the main features of the elastoplastic and damage DSS model. A detailed description of this theory is available in a previous work of the authors [11], where the Lemaitre's formulation [13] was adopted for the description of the ductile damage evolution. The present work considers a different approach, based on the modified Mohr-Coulomb criterion as presented by Bai and Wierzbicki [12]. Moreover, an additional modification of the ductile damage evolution law is here introduced to describe the difference in ductility under proportional and non-proportional loading paths. Therefore, the discussion is initially focused on the definition of proportional and non-proportional loads.

According to the present literature [14,15], a load can be defined as proportional whenever the ratio among the principal stresses does not change during the loading. To this category belong, for example, uniaxial tension/compression, pure shear, or more complex conditions where the stress tensor components change 'proportionally'. On the contrary, nonproportional loads are defined as all the types of loading that do not meet the previous condition. An example of proportional and non-proportional loading paths is schematically described in Fig. 1a.

Hashiguchi and Tsutsumi [16] pointed out that in the traditional elastoplasticity, assuming an associated flow rule and a single smooth plastic potential, the generation of plastic deformation depends uniquely on the component of the stress rate along the normal to the plastic potential. This aspect becomes particularly relevant whenever the stress path deviates significantly from the proportional loading, as for example in instability phenomena with localization and/or bifurcation of the deformation. In this case, during the loading process, the stress rate deviates from the normal to the plastic potential due to a component of the stress rate directed along the tangent to the plastic potential, called tangential stress rate. Hashiguchi and Tsutsumi proposed a novel constitutive model to include the inelastic contribution (i.e. tangential plastic strain) generated by the tangential stress rate component to correct the overestimation of the material stiffness predicted by traditional models with a single smooth plastic potential.

The fundamental concept of this paper is the inclusion of an additional inelastic stretching, the tangential plastic strain, to the ductile damage evolution law in order to explain the different failure mechanism under non-proportional loading paths. 
It is worth mentioning that the novel damage accumulation law can be applied to a general loading path, since the contribution of the inelastic strain depends on the orientation of the total stress rate.

\section{The Damage Subloading Surface model}

This subsection deals with the constitutive equations of the DSS. Starting from the definition of the additive decomposition of the total strain rate tensor, the expression of the co-rotational rate of the Cauchy stress is obtained. The theoretical framework and the main variables are here briefly introduced, for a complete discussion of the model please refer to [11]. The DSS model is a coupled elastoplastic and damage model that derives its formulation from a previous unconventional plasticity theory, named Extended subloading surface model (i.e. SS) [15]. The choice of an unconventional plasticity model [17] is mainly due to the ability of the SS theory to give a realistic description of the plastic strain accumulation and of the material ratcheting for cyclic mobility problems and for fatigue life investigations. In fact, this approach has been used successfully in different numerical analyses focused on predicting low- and high- cycle fatigue life [18,19], assessing welded structures [20, 21], and generally for analyzing the deformation behavior of metallic [22, 23] and granular [24-26] materials.

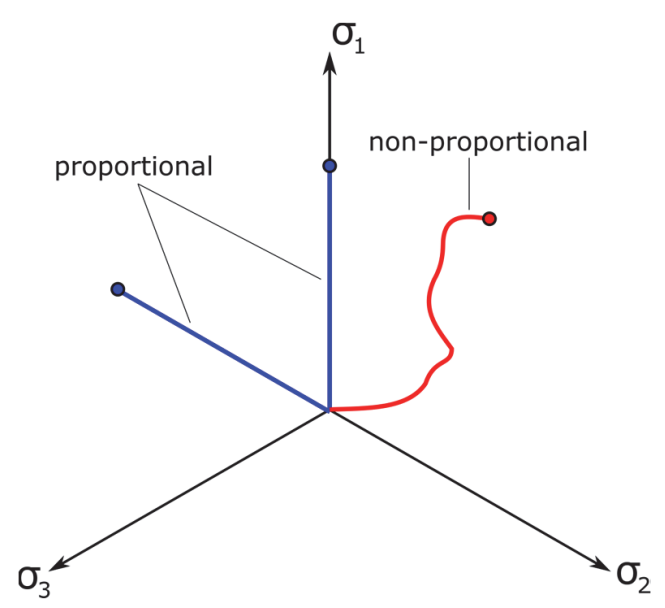

a)

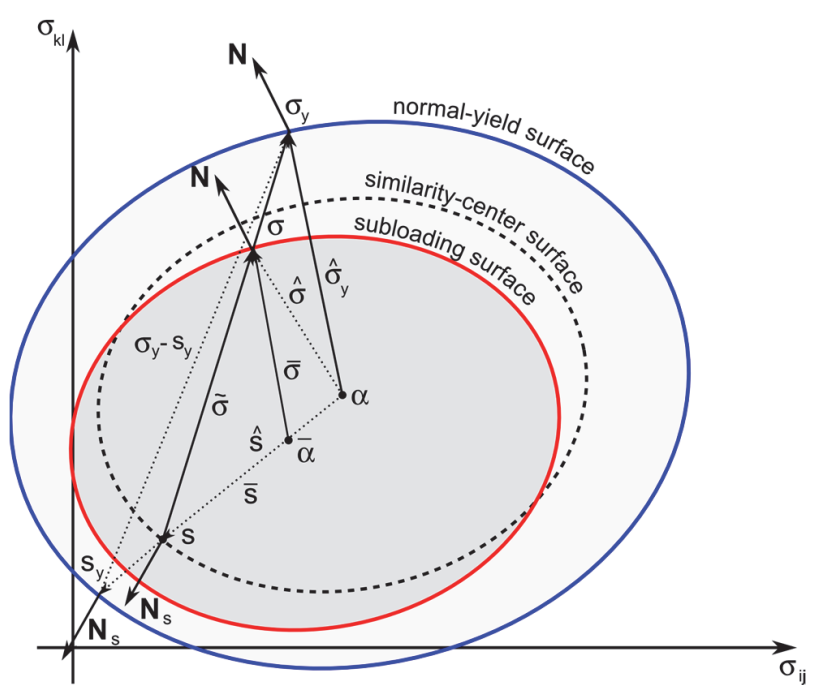

b)

Figure 1: a) Loading paths for proportional and non-proportional loading, b) sketch of the normal-yield and subloading surface.

The main feature of the SS consists in the abolition of the neat distinction between the elastic and plastic domains, stating that irreversible deformations can be generated whenever the loading criterion is satisfied. In order to achieve this goal a second surface, named subloading surface, is generated by means of a similarity transformation from the conventional yield surface, here renamed normal yield-surface (see Fig. 1b). The subloading surface is defined to pass always through the current stress state, assuming the role of a loading surface that expands and contracts in the stress space depending on the loading or unloading of the material. The center of similarity $\boldsymbol{s}$ is not fixed in the stress space but it can move following the plastic strain rate (its speed is regulated by the material parameter c). Some limitations were introduced by Hashiguchi [15] to prevent the protrusion of the similarity-center beyond the yield surface, which would lead to theoretical and numerical inconsistencies. In detail, a third surface, the similarity-center surface, is created as the locus of points for the similarity center and its size is regulated by a material parameter $\chi$, see Fig. 1 b.

The present work assumes a finite elastoplasticity framework that adopts a hypoelastic base plasticity. In this context, the total strain rate tensor $\mathbf{D}$ is additively decomposed into an elastic part $\mathbf{D}^{e}$ and a plastic part $\mathbf{D}^{p}$ according to

$$
\mathbf{D}=\mathbf{D}^{e}+\mathbf{D}^{p}
$$

The expression of the co-rotational rate of the Cauchy stress can be obtained from the previous Eqn. (1) through some mathematical manipulations. In the following lines, it will be shown how to re-write the elastic and plastic strain rates as functions of the stress rate. The elastic part of the stress rate is related to the co-rotational rate of the Cauchy stress by means of the fourth-order elasticity tensor pre-multiplied by the weakening function (1-D), following the approach proposed by Lemaitre [13]. 


$$
\mathbf{D}^{e}=(1-D) \mathbf{E}^{-1}: \stackrel{\circ}{\sigma} \quad \stackrel{\AA}{\mathbf{A}}=\dot{\mathbf{A}}-\mathbf{w} \mathbf{A}+\mathbf{A} \mathbf{w}
$$

Eqn. (2) 2 defines the co-rotational rate for a generic second-order tensor $\boldsymbol{A}$, being $\boldsymbol{w}$ the spin of the rigid-body rotation. The analytical expression of the plastic strain rate passes through the definition of the normal-yield and subloading surface, here coupled with the isotropic scalar variable $D$.

$$
f(\hat{\boldsymbol{\sigma}})=(1-D) F(H) ; \quad f(\overline{\boldsymbol{\sigma}})=(1-D) R F(H) ; \quad \hat{\boldsymbol{\sigma}}=\boldsymbol{\sigma}-\boldsymbol{\alpha} \quad \overline{\boldsymbol{\sigma}}=R \hat{\boldsymbol{\sigma}}=\boldsymbol{\sigma}-\bar{\alpha}, \quad \bar{\alpha}=\mathbf{s}-R \hat{\mathbf{s}}, \quad \hat{\mathbf{s}}=\mathbf{s}-\boldsymbol{\alpha}
$$

The function $f$ is a generic yield-stress scalar function, herein the von Mises criterion is assumed. The similarity ratio $R$ expresses the ratio between the normal-yield and the subloading surface and it characterizes the stress state. For $0 \leq R<1$ the stress belongs to the sub-yield state, inside the normal-yield surface. For $R=1$ the stress lies on the normal-yield surface (which coincides with the subloading surface) and it belongs to the fully plasticized state. The expression of the similarity ratio is given in its incremental form during the loading (Eqn.(4) 1 ). Where $\dot{R}$ depends on the material parameter $u$ and the norm of the plastic strain tensor. The term $R_{e}$ defines the size of an eventual sub-elastic domain, introduced by Tsutsumi et al. [27] to model metallic materials. However, during the elastic unloading, the similarity ratio can be computed by the analytical formula in Eqn.(4)2. The symbol " " indicates the deviatoric part of the tensor. Fincato and Tsutsumi in [11] defined the similarity ratio formulas for the DSS model.

$$
\left[\begin{array}{ll}
\dot{R}=U(R)\left|\mathbf{D}^{p}\right| ; \quad U(R)=u \cot \left(\frac{\pi}{2} \frac{\left\langle R-R_{e}\right\rangle}{1-R_{e}}\right) & \text { during loading } \\
R=\frac{\operatorname{tr}\left(\tilde{\boldsymbol{\sigma}}^{\prime} \hat{\mathbf{s}}^{\prime}\right)+\sqrt{\operatorname{tr}^{2}\left(\tilde{\boldsymbol{\sigma}}^{\prime} \mathbf{s}^{\prime}\right)+\left(\frac{2}{3}(1-D)^{2} F^{2}-\left|\hat{\mathbf{s}}^{\prime}\right|^{2}\right)\left|\tilde{\boldsymbol{\sigma}}^{\prime}\right|^{2}}}{\left(\frac{2}{3}(1-D)^{2} F^{2}-\left|\hat{\mathbf{s}}^{\prime}\right|^{2}\right)} & \text { during unloading. }
\end{array}\right.
$$

The consistency condition of Eqn. (3) 2 and the similarity ratio expression of Eqn. (4) 2 require the definition of the similarity center $\boldsymbol{s}$, the back stress $\boldsymbol{\alpha}$ and the isotropic-hardening function $F$. Briefly, their expressions are reported in the following Eqs. (5)-(7), respectively.

$$
\begin{aligned}
& \stackrel{\circ}{\mathbf{s}}=c\left|\mathbf{D}^{p}\right|\left(\frac{\tilde{\sigma}}{R}-\left(\frac{1}{\chi}-1\right) \hat{\mathbf{s}}\right)+\stackrel{\circ}{\alpha}+\left(\frac{d F}{d H} \frac{1}{F} \dot{H}\right) \hat{\mathbf{s}}-\frac{\dot{D}}{(1-D)} \hat{\mathbf{s}} \\
& F=F_{0}+K\left\langle H-H_{p}\right\rangle+F_{0} b_{1}\left[1-e^{-b_{2}\left\langle H-H_{p}\right\rangle}\right] \\
& \stackrel{\circ}{\stackrel{\circ}{i}_{i}}=\left(C_{i} \mathbf{D}^{p}-\lambda B_{i} \boldsymbol{\alpha}_{i}\right) ; \quad \stackrel{\circ}{\alpha}=\sum_{i=1}^{n} \stackrel{\circ}{\alpha}_{i}, \quad n=1, \ldots N
\end{aligned}
$$

As mentioned at the beginning of this section the similarity-center movement depends on the norm of the plastic strain rate together with the material constants $c$ and $\chi$. The rate form of the damage variable $\dot{D}$ will be discussed in the following subsection. The isotropic-hardening function of Eqn. (6) depends on four material parameters $h_{1}, h_{2}, K$ and $H_{p}$. The first two constants have the same meaning as in [15], $K$ gives an additional linear contribution, whereas $H_{p}$ was introduced by the authors to model a strain hardening plateau. The kinematic hardening law of Eqn. (7) was introduced by Chaboche [28] to define the back stress rate as the linear combination of $N$ non-linear contributions, regulated by the material constants $C_{i}$ and $B_{i}$. In the present paper $N$ was set to be equal to two.

The DSS model considers an associated flow rule for the generation of the plastic strain rate tensor $\mathbf{D}^{p}$. Consequently, the plastic deformations are generated along the normal tensor $\boldsymbol{N}$ to the plastic potential at the current deviatoric stress state $\bar{\sigma}^{\prime}$. 


$$
\mathbf{D}^{\mathrm{p}}=\frac{\mathbf{N}: \stackrel{\circ}{\sigma}}{\mathrm{M}^{\mathrm{p}, \mathrm{D}}} \mathbf{N} ; \quad \mathbf{N}=\frac{\overline{\boldsymbol{\sigma}}^{\prime}}{\left|\overline{\boldsymbol{\sigma}}^{\prime}\right|} ; \quad|\mathbf{N}|=1
$$

The term $\mathrm{Mp}, \mathrm{D}$ in Eqn. (8) $)_{1}$ is the elastoplastic modulus coupled with the damage. Its definition is derived by means of some mathematical manipulations from the consistency condition of Eqn. (3), as shown in [11].

$$
M^{p, D}=\mathbf{N}:\left[\left(\frac{d F}{d H} \frac{1}{F} \sqrt{\frac{2}{3}}(1-D) \hat{\boldsymbol{\sigma}}+\frac{\stackrel{\circ}{\alpha}}{\left|\mathbf{D}^{p}\right|}+U \frac{\tilde{\sigma}}{R}+(1-R) c\left(\frac{\tilde{\sigma}}{R}-\left(\frac{1}{\chi}-1\right) \hat{\mathbf{s}}\right)-\sqrt{\frac{2}{3}} \frac{(1-D)}{\lambda} \dot{D} \hat{\boldsymbol{\sigma}}\right)\right]
$$

Finally, combining the expressions of Eqs. (2) and (8) 1 into Eqn. (1) it is possible to obtain the co-rotational stress rate as a function of the total strain rate as follows

$$
\stackrel{\circ}{\boldsymbol{\sigma}}=\left[\overline{\mathbf{E}}-\frac{\overline{\mathbf{E}} \mathbf{N} \otimes \overline{\mathbf{E}} \mathbf{N}}{M^{p, D}+\mathbf{N}: \overline{\mathbf{E}}: \mathbf{N}}\right] \mathbf{D}
$$

\section{The ductile damage evolution law for proportional and non-proportional loading paths}

Following a well-consolidated approach adopted by the continuum damage mechanics an arbitrary stress state can be described by using two dimensionless parameters: the stress triaxiality ST and the Lode angle parameter LA, defined as in Eqn. (11):

$$
\eta=\sigma_{m} / \sigma_{\text {Mises }} \quad \bar{\theta}=1.0-(6 \theta / \pi)
$$

In particular, the Lode angle parameter field of existence covers all the possible loading conditions, from the uniaxial extension to the uniaxial compression passing by the pure shear (or plane strain) condition where it assumes null value. Therefore, every pair of variables $(\eta, \bar{\theta})$, representing a unique stress state, can be used in the formulation of fracture envelope in the MC criterion. This criterion has been widely and successfully used in the prediction of the failure behavior of granular materials such as rock, soil and concrete. Recent applications [9,12,29], adopted successfully the MC criterion in investigations on metals ductility. The expression of the MC failure envelope can be found in [12], where Bai and Wierzbicki presented an analytical formula function of the two variables, ST and LA, and of eight material parameters. However, in case the effects of the pressure and of the LA on plasticity could be considered as negligible, a von Mises potential can be assumed and then the expression can be simplified in the following:

$$
\bar{\varepsilon}_{f}=\left\{\frac{A}{c_{2}}\left[\sqrt{\frac{1+c_{1}^{2}}{3}} \cos \left(\frac{\bar{\theta} \pi}{6}\right)+c_{1}\left(\eta+\frac{1}{3} \sin \left(\frac{\bar{\theta} \pi}{6}\right)\right)\right]\right\}^{-\frac{1}{N}}
$$

where $A, c_{1}, c_{2}$ and $N$ are four user defined material parameters. Based on the previous Eqn. (12) the ductile damage evolution law can be written as

$$
\dot{D}=\frac{\sqrt{2 / 3}\left|\mathbf{D}^{p}\right|}{\bar{\varepsilon}_{f}(\eta, \bar{\theta})} \mathrm{H}\left[H-d_{1}\right]
$$

where the constant $d_{1}$ is introduced to allow the damage to evolve after a certain amount of plastic deformations. The previous Eqn. (13) offers a good description of the damage evolution during proportional loading [30], however, it cannot explain the damage acceleration during the non-proportionality of the load.

As recalled at the beginning of the theoretical framework section, the non-proportionality triggers a non-negligible component of the stress rate along the tangent to the plastic potential. Therefore, the main idea is to add to the ductile damage evolution an additional inelastic contribution, herein called tangential plastic strain rate $\mathbf{D}^{t}$, generated by the stress rate component tangential to the Mises potential. The tangential inelastic strain rate can be evaluated adopting the same assumptions proposed by Rudnick and Rice [31] and Hashiguchi and Tsutsumi in [16]. In particular: 
- Only the deviatoric part of the stress is responsible for the inelastic stretch, which allows us to conclude that the tangential inelastic strain is triggered by the deviatoric tangential component of the stress rate.

- The tangential stretching $\mathbf{D}^{t}$, as well as the plastic stretching $\mathbf{D}^{p}$, smoothly develop with the similarity ratio $\mathrm{R}$ (i.e. $\mathbf{D}^{t}$ is a function of the similarity ratio).

- The tangential stretching does not contribute to the material hardening [15].

- the tangential stretching is linearly related to the co-rotational stress rate.

In detail, the last hypothesis was introduced to obtain a simple constitutive model that could be used in general loading paths. In fact, more complex corner theories limit the application to simple loading cases. The tangential plastic strain rate can be written as

$$
\mathbf{D}^{t}=\frac{A}{2 \bar{G}} \stackrel{\circ}{\sigma}_{t}^{\prime} ; \quad \stackrel{\circ}{\sigma}_{t}^{\prime}=\hat{\mathbf{I}}^{\prime} \stackrel{\circ}{\boldsymbol{\sigma}}=\left(\overline{\mathbf{I}}-\frac{1}{3} \mathbf{I} \otimes \mathbf{I}-\mathbf{N} \otimes \mathbf{N}\right) \stackrel{\circ}{\sigma} ; \quad A=\frac{1}{2 \bar{G}}\left(\frac{T_{1} R^{T_{2}}}{1-T_{1} R^{T_{2}}}\right)
$$

where $A$ is a scalar variable, function of the shear modulus $G$ pre-multiplied by the (1-D) factor (i.e. $\bar{G}=G(1-D)$ ), the similarity ratio $R$ and two material parameters $T_{1}\left(0 \leq T_{1}<1\right)$ and $T_{2}\left(0 \leq T_{2}\right)$. In particular, if $T_{1}$ is equal to zero no tangential plastic strain rate is generated, on the other hand, if $T_{1}$ tends to unity and assuming a fully plasticized state (i.e. $R$ $=1$ ) the tangential plastic strain rate is maximized. The term $\hat{\mathbf{I}}^{\prime}$ in Eqn. (14) 2 is the fourth-order deviatoric tangential (orprojection) tensor [15] and it is function of the fourth-order identity tensor $\overline{\mathbf{I}}$ and the second-order identity tensor $\mathbf{I}$. In conclusion, the ductile damage evolution law of Eqn. (13), can be rewritten to consider the additional inelastic contribution of Eqn. (14)1 as

$$
\dot{D}=\frac{\left(\sqrt{2 / 3}\left|\mathbf{D}^{p}\right|+T_{3}\left|\mathbf{D}^{t}\right|\right)}{\bar{\varepsilon}_{f}(\eta, \bar{\theta})} \mathrm{H}\left[H-d_{1}\right] ; \quad H^{i}=\int \sqrt{2 / 3}\left|\mathbf{D}^{p}\right|+\int T_{3}\left|\mathbf{D}^{p}\right|=H^{D}+H^{T}
$$

The constant $T_{3}\left(0 \leq T_{3} \leq 1\right)$ has been introduced to regulate the amount of the contribution of the tangential stretching to the damage. The second of Eqn. (15) reports the cumulative inelastic strain variable $H^{i}$, as the sum of the cumulative plastic strain $H^{D}$ and the cumulative tangential plastic strain $H^{T}$. The advantage of the law in Eqn. (15) ${ }_{1}$ is that the damage is subjected to an additional contribution uniquely when the stress rate deviates from the normal to the plastic potential. Therefore, it is suitable to describe the failure behaviour under both proportional and non-proportional loading paths.

\section{NUMERICAL ANALYSES}

he numerical analyses in this paper were carried out by implementing the previous set of constitutive equations via user subroutine for the commercial code Abaqus (ver. 6.14-5). The section is subdivided in two sub-sections. The first example deals with a two steps loading of a plate element with the scope of showing the features of the ductile damage law in Eqn. (15)1. The second numerical example shows an application of the DSS model to describe the structural response of a thin wall bridge pier under cyclic non-proportional loading, reproducing the experimental results carried out by Nishikawa et al. [32].

\section{Two step loading example}

This numerical example consists in subjecting a plate element, under the assumption of plane strain, to a sequence of two different loading conditions. During the first step (i.e. step 1) the plate is pulled, under uniaxial boundary conditions, up to $10 \%$ of the nominal axial strain. Subsequently, a simple shear condition is applied to generate a $20 \%$ angular distortion (i.e. step 2). Please refer to the sketch of Fig. 2a. The numerical test was designed this way to maximize the effect of the tangential plastic strain. In fact, after the uniaxial extension, the stress state belongs to a fully plasticized state, where the similarity ratio $R$ equal to unity gives the maximum contribution according to Eqn. (14)3. Moreover, the sudden change of direction between the loading step 1 and the loading step 2 triggers a non-negligible component of the stress rate along the tangent to the plastic potential. 


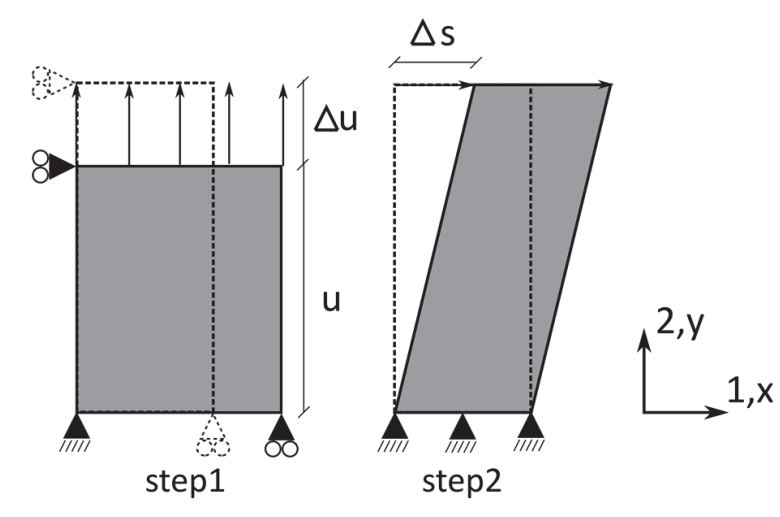

a)

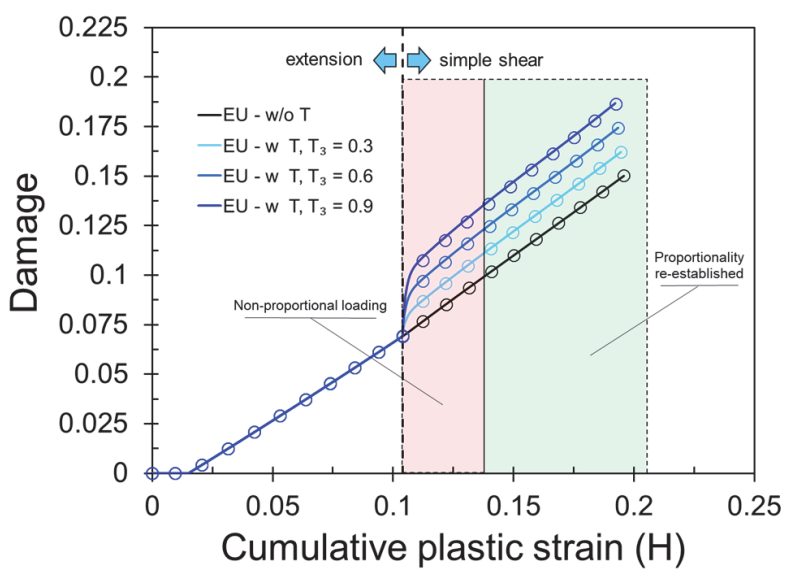

b)

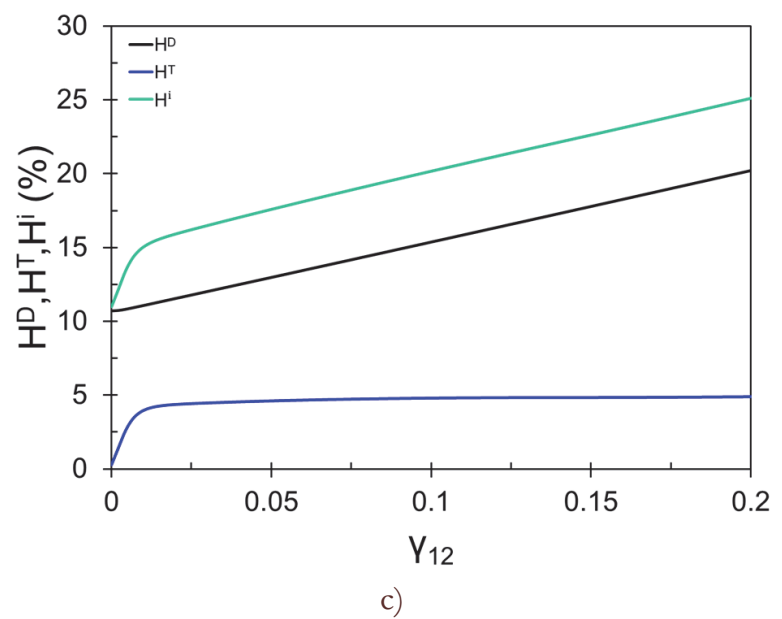

Figure 2: a) sketch of the plate subjected to two loading steps; b) ductile damage evolution depending on the material parameter $T_{3}$. c) cumulative inelastic strain $H^{i}$, cumulative plastic strain $H^{D}$ and cumulative tangential plastic strain $H^{T}$ vs. angular distortion.

For sake of convenience, the material parameters adopted in this first study case are the same of the ones used for the numerical analysis of the thin wall steel pier. The calibration and the discussion of their values will be dealt in the next subsection. The actual values of the material constants are relatively important in this study case, since the primary goal is to show the characteristic of the ductile damage evolution law described in Eqn. (14)1.

Fig. $2 \mathrm{~b}$ reports the damage evolution through the step 1 and the step 2 for different values of the parameter $T_{3}$. During the first loading step, the damage evolves in the same way, independently from the value of the $T_{3}$ constant, since the load is proportional. However, at the beginning of step 2 the damage evolution accelerate proportionally to $T_{3}$, as a consequence of the rotation of the directions of the principal stresses, triggered by the sudden change of loading conditions. Experimental results, reported by Roscoe [33] for granular materials, also confirm the non-coaxiality of the principal stresses and the principal plastic strains directions for the simple shear test. However, this tendency tends to disappear at large strains where the proportionality of the load tends to be re-established. This phenomenon can be seen in Fig. $2 \mathrm{~b}$, after the initial acceleration of the damage accumulation, the evolution rate slows down and the blue lines became parallel to the black one. Therefore, the damage evolution accelerates whenever the loading conditions trigger a rotation of the directions of the principal stresses, whereas it proceeds with the same rate as in Eqn.(13) when the proportionality is re-established. Fig. 2c reports the cumulative inelastic strain $H^{i}$, cumulative plastic strain $H^{D}$ and cumulative tangential plastic strain $H^{T}$ (see Eqn. (15)) against the angular distortion for the second loading step. The contribution of the tangential plastic strain is around the $20 \%$ of the total cumulative inelastic strain.

\section{Thin wall steel column under cyclic loading}

This second numerical analysis focuses the attention on reproducing the structural response of a steel column subjected to unidirectional cyclic loading. The damage evolution was monitored considering or not the tangential plasticity term (i.e. Eq 
(13) or (15)), pointing out the necessity to include the additional inelastic stretching contribution for a more realistic description of the material behavior.

Nishikawa et al. [32] conducted a series of experiments on thin steel piers in order to analyze the horizontal load-carrying capacity of the structures subjected to an increasing unidirectional horizontal load. The schematic of the pier is reported in Fig. 3 a together with its FE modeling. The loading sequence is instead reported in Fig. 3b. In order to save computational time, just half of the column was considered, applying symmetric boundary conditions. Moreover, the experimental results showed that the plastic deformations, and the buckling, appear in a region close to the base of the pier. Therefore, the structure was modeled according to its real geometry until a height equal to two times the internal diameter from the bottom and the remaining part was modeled with a beam element. A similar strategy was adopted by Gao et al. [34] and by Ucak and Tsopelas [35]. The geometric specifications are reported in Tab. 1.

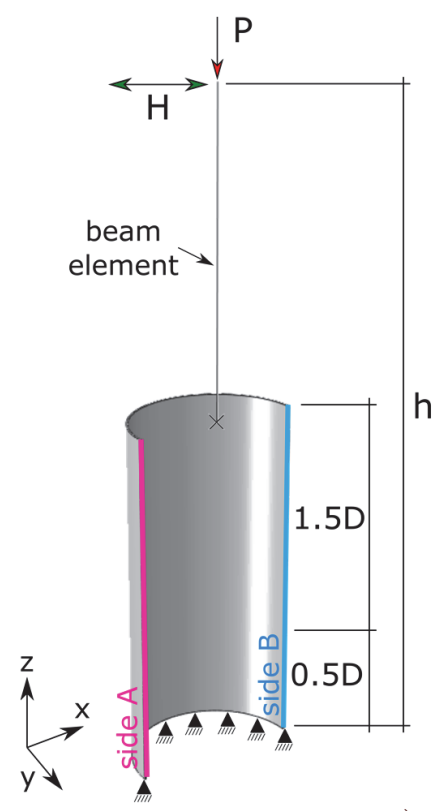

a)
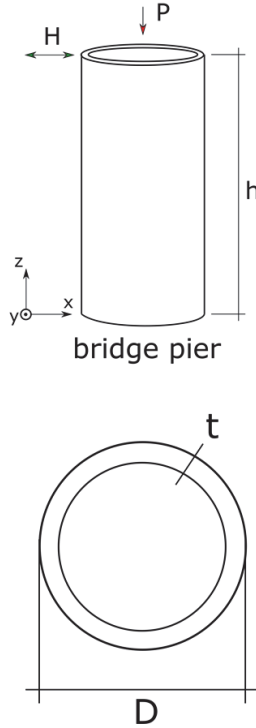

b)

Figure 3: a) Model and geometry of the bridge pier; b) Loading sequence.

The lower part of the pier has a mesh of eight-node hexahedral elements with reduced integration (i.e. Abaqus C3D8R elements) and the nodes of the top cross section were connected to the beam with rigid links. A mesh refinement was considered close to the base of the pier, where the maximum accumulation of plastic deformation is expected. The minimum element size is $9.8 \mathrm{~mm}$ (circumference) x $2.25 \mathrm{~mm}$ (thickness) x $15 \mathrm{~mm}$ (axial), comparable with the minimum element size used by Van Do et al. [36], who conducted a mesh size sensitivity analysis on the same study case. The total number of elements amount to 51841 .

The structure is subjected to two types of loads: a compressive load P, constant and kept for the whole duration of the experiment, and a horizontal load $\mathrm{H}$, directed along the $\mathrm{x}$-direction and with an increasing amplitude. The idea of Nishikawa et al. was to reproduce the conditions of a seismic solicitation hitting a bridge pier, where P represented the dead load of the infrastructure over the steel column and $\mathrm{H}$ represented a simplify shock wave. The magnitude of $\mathrm{P}$ was set to be 0.124 the squash load $\mathrm{P}_{\mathrm{y}}$. The parameters $\mathrm{H}_{\mathrm{y}}$ and $\delta_{\mathrm{y}}$ in Tab. 1 represent the horizontal load and horizontal displacement when the specimen yields close to the base.

A preliminary characterization of the material parameters for the DSS and the material parameters for the definition of the MC failure envelope was carried out by reproducing the uniaxial tensile behavior of a smooth bar reported in [36,37]. Few material parameters such as: the Young's modulus, the Poisson's ratio and the yield stress $F_{0}$ were assumed directly from [32], the kinematic hardening parameters $C_{1}, B_{1}, C_{2}, B_{2}$ and the threshold for the strain plateau $H_{p}$ were assumed as in Van Do et al. [36]. The threshold for the damage evolution $d_{1}$ was chosen to be equal to strain plateau threshold $H_{p}$. The remaining damage parameters in Tab. 3, together with the isotropic hardening parameters $K, b_{1}, h_{2}$ were obtained by minimizing the difference between the numerical and experimental curves reported by Goto et al. [37], as shown in Fig. 4. Two aspects have to be mentioned. Firstly, the calibration of the damage parameters based on a single uniaxial tensile test cannot guarantee to identify the correct set of variables for the description of the ductile behavior of the material. Therefore, the 
parameters in Tab. 3 were adjusted a posteriori to fit both the uniaxial tensile test and the pier behavior. Secondly, the contribution of the tangential plastic term is negligible during the monotonic uniaxial tensile test. The parameters $T_{1}, T_{2}$ and $T_{3}$ were calibrated during the pier analysis. The material constants $c, \chi, u, R_{e}$ regulate the amount of inelastic strain in the sub-yield state and, in general, are calibrated by means of a cyclic loading analysis to fit the material ratcheting [21,23,27]. In the present study, they were calibrated by minimizing the difference of the normalized horizontal load vs. normalized horizontal displacement in the steel pier analysis without taking into account the effect of the damage, see Fig. $5 \mathrm{a}$.

\begin{tabular}{cc}
\hline $\mathrm{h}$ & $3,403[\mathrm{~mm}]$ \\
$\mathrm{t}$ & $8.70[\mathrm{~mm}]$ \\
$\mathrm{D}$ & $891.3[\mathrm{~mm}]$ \\
$\mathrm{P} / \mathrm{P}_{\mathrm{y}}$ & 0.124 \\
$\mathrm{H}_{\mathrm{y}}$ & $414.9[\mathrm{kN}]$ \\
$\delta_{\mathrm{y}}$ & 10.5 \\
\hline
\end{tabular}

Table 1: Structural parameters of the steel bridge pier.

\begin{tabular}{cc}
\hline Young's modulus & $206000[\mathrm{MPa}]$ \\
Poisson's ratio & 0.3 \\
$u$ & 750 \\
$\mathrm{~F}_{0}$ & $294[\mathrm{MPa}]$ \\
$\mathrm{R}_{\mathrm{e}}$ & 0.4 \\
$H_{p}$ & 0.0183 \\
$K, h_{1}, h_{2}$ & $140[\mathrm{MPa}], 0.30,17.0$ \\
$C_{1}, B_{1}$ & $2755[\mathrm{MPa}], 23.01$ \\
$C_{2}, B_{2}$ & $590[\mathrm{MPa}], 22.84$ \\
$c$ & 400 \\
$\chi$ & 0.9 \\
\hline
\end{tabular}

Table 2: Material parameters for the DSS model

\begin{tabular}{cc}
\hline$A$ & $700[\mathrm{MPa}]$ \\
$N$ & 0.25 \\
$c_{1}$ & 0.15 \\
$c_{2}$ & $480[\mathrm{MPa}]$ \\
$d_{1}$ & 0.0183 \\
$T_{1}$ & 0.99 \\
$T_{2}$ & 1.0 \\
$T_{3}$ & 0.6 \\
\hline
\end{tabular}

Table 3: Damage material constants for the Mohr-Coulomb criterion, Eqn. (12) and Eqn. (15). 


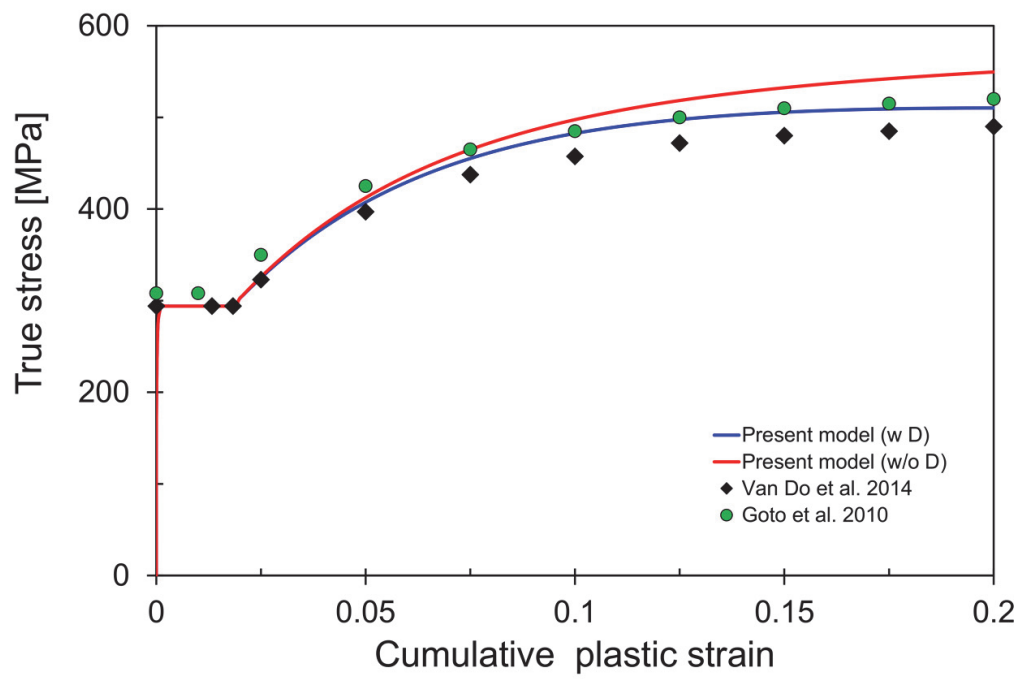

Figure 4: Calibration of the material parameters of the DSS on a uniaxial tensile test.

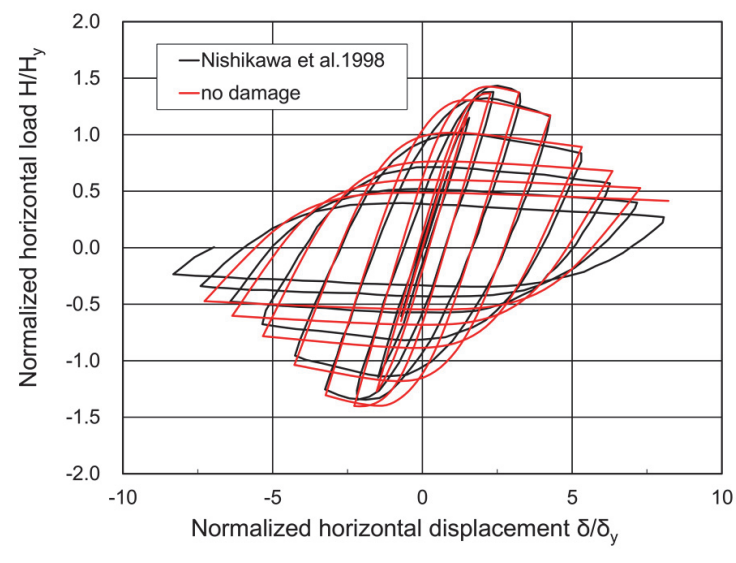

a)

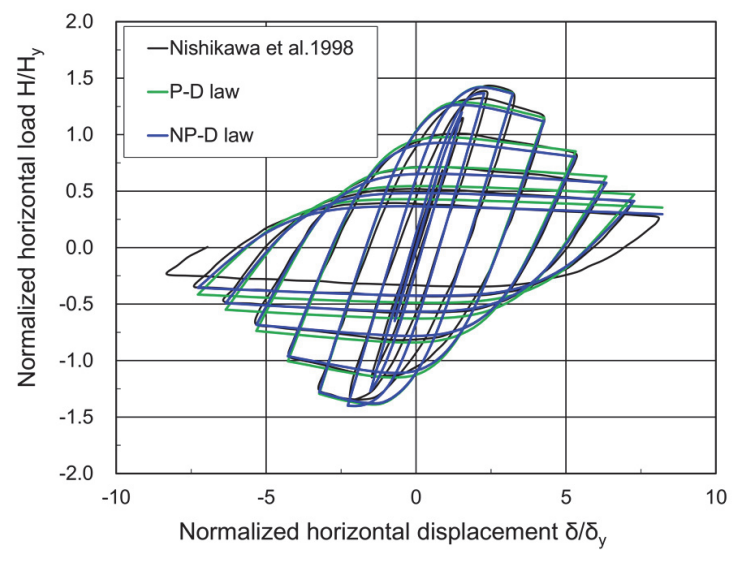

b)

Figure 5: Hysteresis loops for the thin steel pier a) without damage, b) with damage, evolution laws of Eqn. (13) P-D law and Eqn. (15) NP-D law.

Fig. $5 \mathrm{~b}$ shows the effect of the tangential plasticity contribution on the hysteresis loops for the pier, as a consequence of the ductile damage acceleration. The green line refers to the ductile damage evolution of Eqn. (13), the acronym used in the legend P-D stands for proportional damage law, in contrast with the blue line, obtained with Eqn. (15), where the acronym NP-D stands for non-proportional damage law. As it can be seen the green line does not reproduce correctly the experimental results in the last cycles. However, a different calibration of the damage parameters focused to improve the pier behaviour description in the last part of the analysis, led to an underestimation of the material performances in the modelling of the monotonic uniaxial tensile test and in the description of the first five cycles of the column analysis. On the other hand, the solution carried out with a non-proportional damage law is able to catch a realistic hysteresis behaviour of the pier and at the same time to be in good agreement with the experimental results of the tensile test.

The difference between the P-D and the NP-D laws can be observed in Fig. 6 where the value of the horizontal load is reported in correspondence of the unloading points. Both the green and blue lines seem to overestimate the elastic response of the structure, however, the difference can be considered as acceptable. The peak is well described in the load envelope of the positive side of the lateral displacements, whereas there is an overestimation of about the $10 \%$ of the peak load at the third loading cycle in the negative envelope. The post-peak behaviour described by the NP-D law is in very good agreement with the experimental data. 


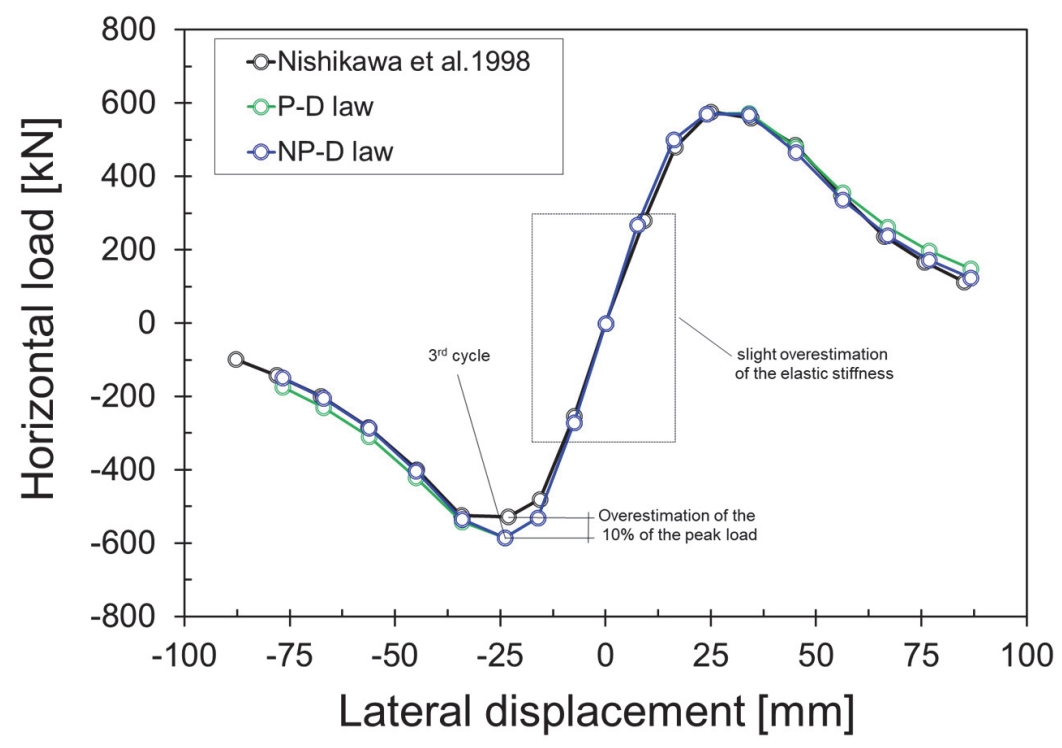

Figure 6: Envelope curves reporting the horizontal loads in correspondence of the unloading points.

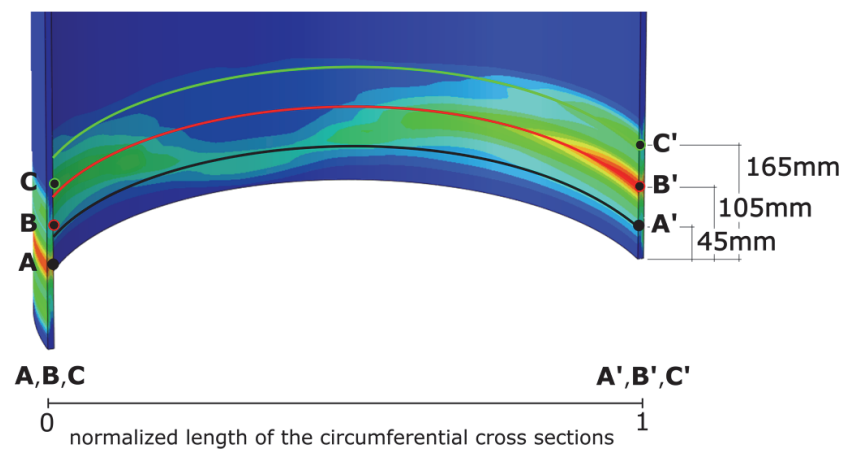

a)

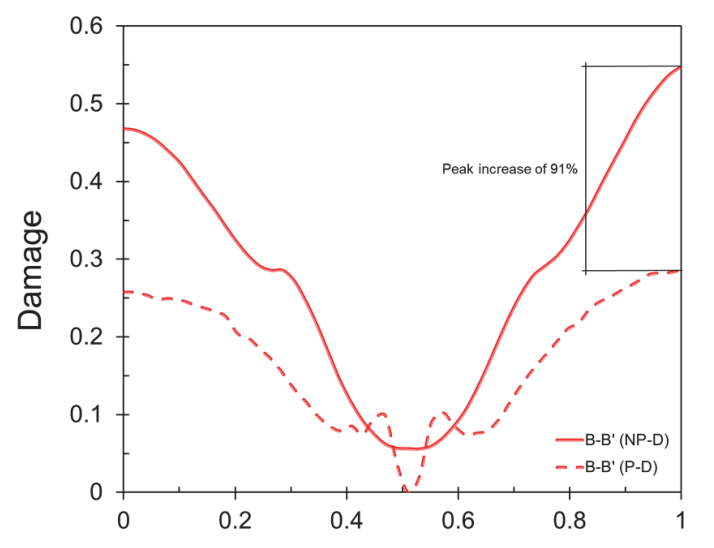

Normalized circumferential cross section length c)

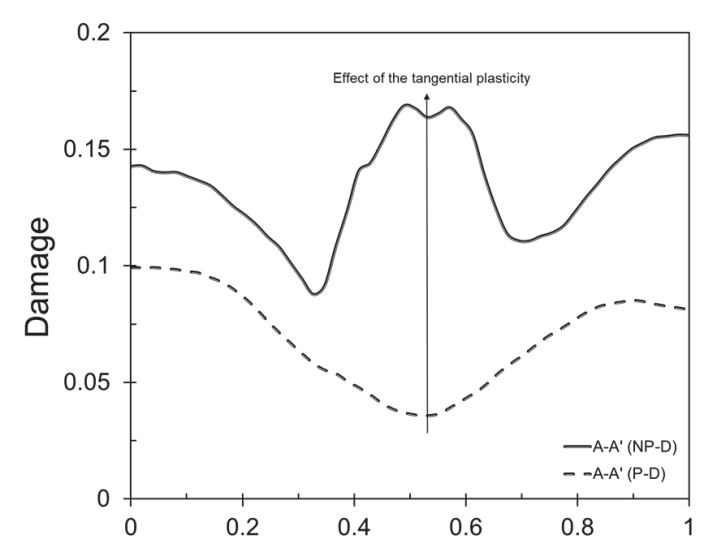

Normalized circumferential cross section length

b)

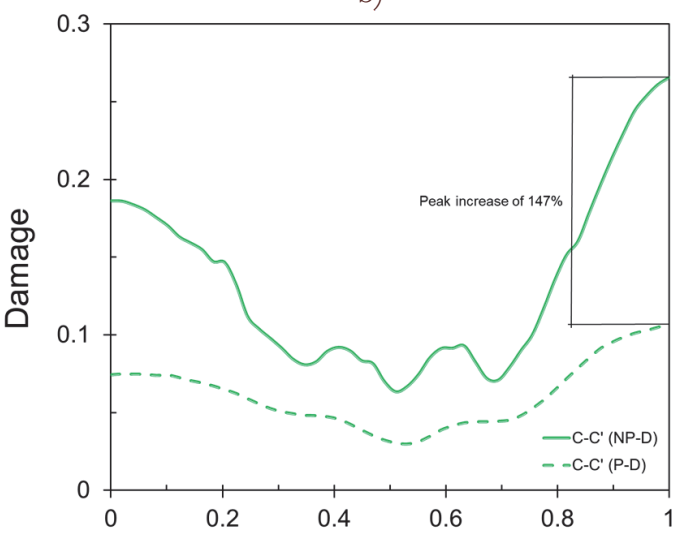

Normalized circumferential cross section length d)

Figure 7: a) Sketch for the evaluation of the damage level along three cross sections, (non-deformed shape) b) damage level along the cross section A-A', c) damage level along the cross section B-B', d) damage level along the cross section C-C'. 


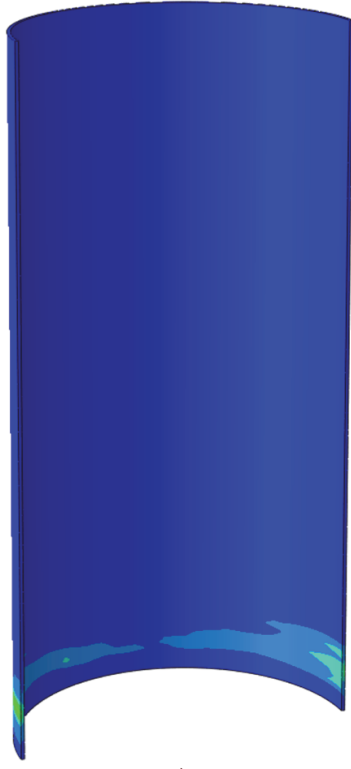

a)

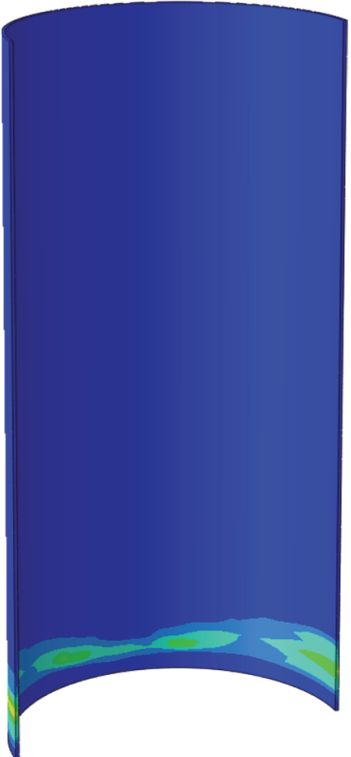

b)

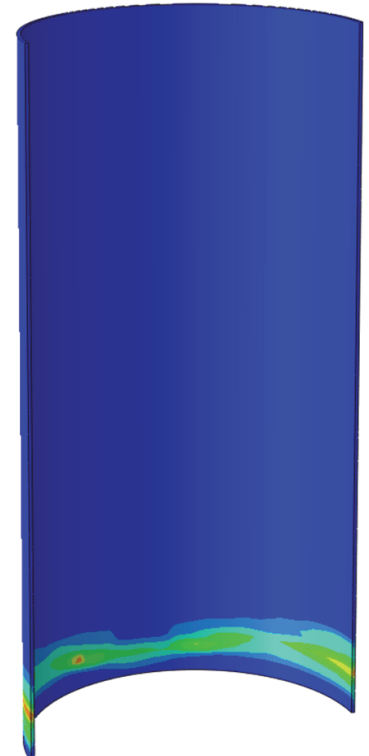

c)

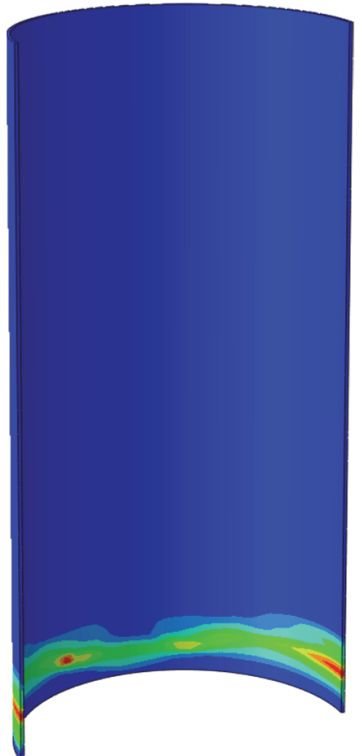

d)

Figure 8: cumulative tangential plastic strain at a) the end of the $5^{\text {th }}$ cycle, b) the end of the $6^{\text {th }}$ cycle, c) the end of the $7^{\text {th }}$ cycle, d) the end of the $8^{\text {th }}$ cycle.

On a local scale, the damage has been investigated along the three circumferential cross sections schematically illustrated in Fig. 7a. The three cross sections indicated with the marks A-A', B-B' and C-C' are located at $45 \mathrm{~mm}, 105$, and 165 mm from the base of the pier, respectively. Fig. $7 b, c$ and $d$ report the corresponding ductile damage level at the end of the $8^{\text {th }}$ loading cycle.

One first observation is that the effect of the tangential plasticity on the damage seems to be more relevant around half of the circumferential length for smaller distances from the pier base. In fact, the two solutions NP-D and P-D in Fig. 7b show a complete difference tendency at the 0.5 value on the $\mathrm{x}$-axis. The more the distance increases from the base of the column the more the effect becomes small.

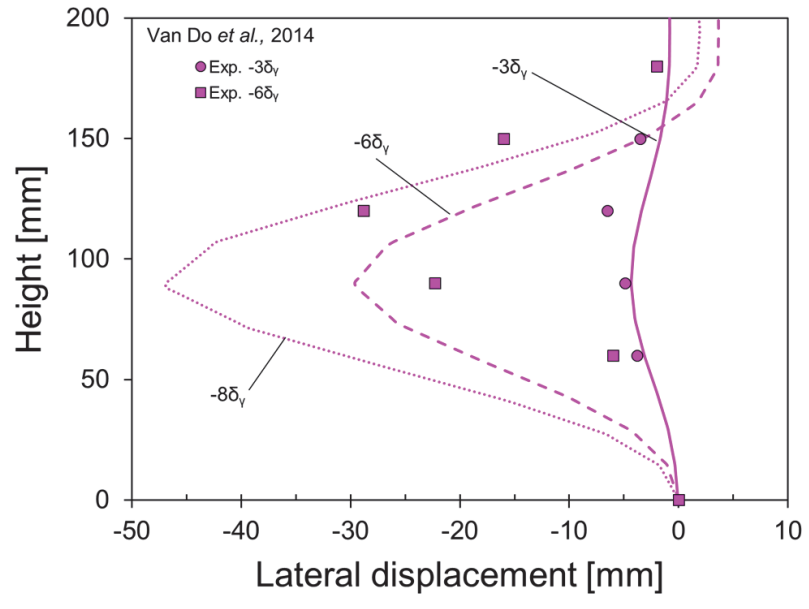

a)

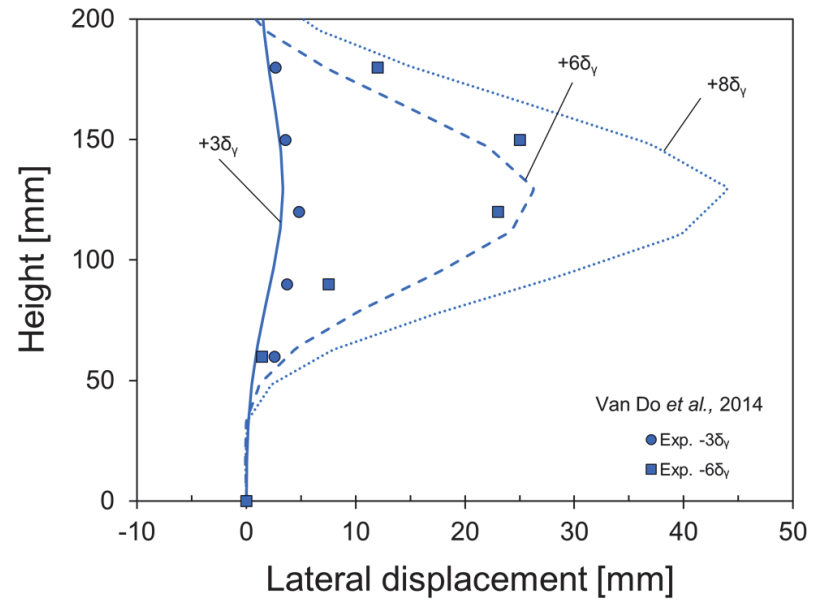

b)

Figure 9: lateral displacements at the loading points for the prescribed displacements amplitudes $\pm 3 \delta_{\mathrm{y}}, \pm 6 \delta_{\mathrm{y}}$ and $\pm 8 \delta_{\mathrm{y}}$ for a) SIDE A and b) SIDE B of Fig. 3a.

A second conclusion is that the damage is maximized for the points located along the loading direction in the graphs of Fig. $7 \mathrm{~d}$ and c (i.e. the points B, C, B' and C'). Here, both the solutions NP-D and P-D have peaks in the damage accumulation in correspondence of the points B' and C'. In detail, the point B' shows the highest absolute peak with a value of $D \approx 0.54$. Van Do et al. [36] obtained a similar peak value, using a different damage accumulation law for the same study case. 
Moreover, the effect of the tangential plasticity is again quite relevant, increasing the values of the P-D damage in B' and C' of $91 \%$ and $147 \%$, respectively. This phenomenon is due to the fact that in correspondence of the points along the loading direction (i.e. the points A, B, C, A', B' and C') the stress state keeps alternating between two extremes of tension and compression, constantly triggering a non-negligible component of the tangential stress rate, see Fig. 8.

The magnitude of the cumulative tangential plastic strain rate is higher around $105 \mathrm{~mm}$ from the column base due to the effect of the compressive load P and of the boundary conditions which causes the typical 'elephant foot' buckling mode. The magnitude of the lateral displacements for the SIDE $A$ and SIDE B (see Fig. 3a) is reported in the following Fig. 9. In detail, the two graphs in Fig. 9 display the computed radial displacements at the unloading points where the displacement amplitudes are $\pm 3 \delta_{\mathrm{y}}, \pm 6 \delta_{\mathrm{y}}$ and $\pm 8 \delta_{\mathrm{y}}$. A comparison with the experimental data reported in [36] is also offered for the conditions $\pm 3 \delta_{\mathrm{y}}$ and $\pm 6 \delta_{\mathrm{y}}$. As mentioned before, the buckling takes place at the base of the column between 0 and $200 \mathrm{~mm}$. The DSS model is capable to catch quite well the magnitude of the lateral displacements in both sides. There is a slight underestimation of the heights where the maximum lateral displacements are located, however, this phenomenon is probably due to the welding conditions at the base of the real specimens which influence the deformed shape of the pier. The same mismatch can be observed in the numerical analyses of Van Do et al. [36] and Gao et al. [34].

\section{CONCLUSIONS}

7 he present paper introduced a coupled elastoplastic and damage model for the evaluation of a thin wall steel bridge subjected to unidirectional and bidirectional non-proportional loading. The ductile damage was modeled with a modified version of the Mohr-Coulomb failure criteria that proved to give reliable results not only for granular materials (i.e. soil, rock, concrete) but also for metallic materials [1,9,10,12]. Moreover, the ductile damage evolution law was modified by the authors to take into account a different accumulation during non-proportional loading paths. Experimental works [8-10,38] pointed out that the total deformation at fracture is higher during proportional loading, suggesting that, in case of non-proportional loading, a different mechanism for the damage accumulation has to be considered. In the present paper, the authors took into account a previous idea developed in Hashiguchi and Tsutsumi [16] and in Tsutsumi and Kaneko [25] for explaining the acceleration of the damage during non-proportional loading. The damage rate is a function not only of the plastic strain rate, generated along the normal to the plastic potential, but also of a tangential inelastic stretch generated by a deviatoric component of the stress rate, tangential to the yield surface. It is worth mentioning that this additional contribution arises only during the non-coaxiality of the directions of the principal stresses and strains and it is negligible whenever the coaxiality is re-established. This allows considering the different mechanisms of the ductile damage accumulation during proportional and non-proportional loading conditions. The main results of the paper can be summarized in the following points:

- The implementation of the constitutive equations of the DSS model, with a damage law accounting for the tangential plastic contributions, are shown in a simple two steps numerical example. A damage acceleration, function of material parameters, is triggered whenever non-proportional loading condition are realized.

- The calibration of the model parameters was done reproducing a uniaxial tensile test data for the SS400 steel. The elastoplastic constants, chosen in this work, approximate well the uniaxial behavior of the SS400 steel reported in Goto et al. [37].

- A single experimental test is not enough for the calibration of the MC constants, since the definition of the failure envelope is a non-linear function in the $\left(\eta, \bar{\theta}, \varepsilon_{f}\right)$ space. Therefore, an adjustment of the MC constants was done during the calibration of the steel column subjected to unidirectional loading.

- The investigations on the pier under unidirectional loading revealed that a better approximation of the real structure behavior can be achieved considering the contribution to the damage of the inelastic tangential stretch.

- The analyses on the local behavior of the structure pointed out that the damage accumulation is accelerated considerably by the NP-D law. However, a future campaign of investigation on the crack formation at the base of the structure is needed to characterize the ductile damage behavior of the pier.

Future works will be focused to design experimental and numerical analyses for a better understanding of the ductile damage evolution in non-proportional loading since it still represents an open challenge in the CDM community.

\section{REFERENCES}

[1] Algarni, M., Bai, Y., Choi, Y. (2015). A study of Inconel 718 dependency on stress triaxiality and Lode angle in plastic 
deformation and ductile fracture, Eng. Fract. Mech., 147, pp. 140-157. DOI: 10.1016/j.engfracmech.2015.08.007.

[2] Bai, Y., Teng, X., Wierzbicki, T. (2009). On the application of stress triaxiality formula for plane strain fracture testing, J. Eng. Mater. Technol., 131(2), pp. 021002. DOI: 10.1115/1.3078390.

[3] Bao, Y., Treitler, R. (2004). Ductile crack formation on notched Al2024-T351 bars under compression-tension loading, Mater. Sci. Eng. A, 384(1-2), pp. 385-394. DOI: 10.1016/j.msea.2004.06.056.

[4] Bao, Y., Wierzbicki, T. (2004). On fracture locus in the equivalent strain and stress triaxiality space, Int. J. Mech. Sci., 46(1), pp. 81-98. DOI: 10.1016/j.ijmecsci.2004.02.006.

[5] Brünig, M., Gerke, S., Hagenbrock, V. (2013). Micro-mechanical studies on the effect of the stress triaxiality and the Lode parameter on ductile damage, Int. J. Plast., 50, pp. 49-65. DOI: 10.1016/j.ijplas.2013.03.012.

[6] Papasidero, J., Doquet, V., Mohr, D. (2014). Determination of the Effect of Stress State on the Onset of Ductile Fracture Through Tension-Torsion Experiments, Exp. Mech., 54(2), pp. 137-151. DOI: 10.1007/s11340-013-9788-4.

[7] Faleskog, J., Barsoum, I. (2013). Tension-torsion fracture experiments-Part I: Experiments and a procedure to evaluate the equivalent plastic strain, Int. J. Solids Struct., 50(25-26), pp. 4241-4257.

DOI: 10.1016/j.ijsolstr.2013.08.029.

[8] Cortese, L., Nalli, F., Rossi, M. (2016). A nonlinear model for ductile damage accumulation under multiaxial nonproportional loading conditions, Int. J. Plast., 85, pp. 77-92. DOI: 10.1016/j.ijplas.2016.07.003.

[9] Algarni, M., Choi, Y., Bai, Y. (2017). A unified material model for multiaxial ductile fracture and extremely low cycle fatigue of Inconel 718, Int. J. Fatigue, 96, pp. 162-177. DOI: 10.1016/j.ijfatigue.2016.11.033.

[10] Papasidero, J., Doquet, V., Mohr, D. (2015). Ductile fracture of aluminum 2024-T351 under proportional and nonproportional multi-axial loading: Bao-Wierzbicki results revisited, Int. J. Solids Struct., 69-70, pp. 459-74.

DOI: 10.1016/j.ijsolstr.2015.05.006.

[11] Fincato, R., Tsutsumi, S. (2017). A return mapping algorithm for elastoplastic and ductile damage constitutive equations using the subloading surface method, Int. J. Numer. Methods Eng., 113(11), pp. 1729-1754.

DOI: $10.1002 /$ nme.5718.

[12] Bai, Y., Wierzbicki, T. (2010). Application of extended Mohr-Coulomb criterion to ductile fracture, Int. J. Fract., 161(1), pp. 1-20. DOI: 10.1007/s10704-009-9422-8.

[13] Lemaitre, J. (1985). Coupled elasto-plasticity and damage constitutive equations, Comput. Methods Appl. Mech. Eng., 51(1-3), pp. 31-49. DOI: 10.1016/0045-7825(85)90026-X.

[14] Halama, R., Sedlk, J., Ofer, M. (2012).Phenomenological Modelling of Cyclic Plasticity. Numerical Modelling, InTech.

[15] Hashiguchi, K. (2009). Elastoplasticity theory, vol. 42, Berlin, Heidelberg, Springer-Verlag Berlin Heidelberg.

[16] Hashiguchi, K., Tsutsumi, S. (2001). Elastoplastic constitutive equation with tangential stress rate effect, Int. J. Plast., 17(1), pp. 117-145. DOI: 10.1016/S0749-6419(00)00021-8.

[17] Drucker, D.C. (1988). Conventional and Unconventional Plastic Response and Representation, Appl. Mech. Rev., 41(4), pp. 151. DOI: $10.1115 / 1.3151888$.

[18] Tsutsumi, S., Murakami, K., Gotoh, K., Toyosada, M. (2008). Cyclic stress-strain relation under high cycle fatigue process, J. Japan Soc. Nav. Archit. Ocean Eng., 7, pp. 243-250. DOI: 10.2534/jiasnaoe.7.243.

[19] Tsutsumi, S., Fincato, R., Ohata, M., Sano, T. (2017). Assessment Technology of Fatigue Crack Initiation Life of Weld Structures, Q. J. Japan Weld. Soc., 86(1), pp. 56-58. DOI: 10.2207/jjws.86.56.

[20] Tsutsumi, S., Morita, K., Fincato, R., Momii, H. (2016). Fatigue life assessment of a non-load carrying fillet joint considering the effects of a cyclic plasticity and weld bead shape, Facture Stuctural Integr., 38, pp. 244-250. DOI: $10.3221 /$ IGF-ESIS.38.33.

[21] Fincato, R., Tsutsumi, S. (2017). Numerical study of a welded plate instability using the subloading surface model, Mar. Struct., 55, pp. 104-120. DOI: 10.1016/j.marstruc.2017.05.001.

[22] Tsutsumi, S., Toyosada, M., Murakami, K. (2007). Generation of Plastic Strain due to Constant Cyclic Loading Under Macroscopically Elastic Condition, Trans. Japan Soc. Mech. Eng. Ser. A, 73(730), pp. 724-731. DOI: $10.1299 /$ kikaia.73.724.

[23] Hashiguchi, K., Ueno, M., Ozaki, T. (2012). Elastoplastic model of metals with smooth elastic-plastic transition, Acta Mech., 223(5), pp. 985-1013. DOI: 10.1007/s00707-012-0615-2.

[24] Tsutsumi, S., Hashiguchi, K. (2005). General non-proportional loading behavior of soils, Int. J. Plast., 21(10), pp. 19411969. DOI: 10.1016/j.ijplas.2005.01.001.

[25] Tsutsumi, S., Kaneko, K. (2008). Constitutive response of idealized granular media under the principal stress axes rotation, Int. J. Plast., 24(11) , pp. 1967-1989. DOI: 10.1016/j.ijplas.2008.05.001.

[26] Salomoni, V.A., Fincato, R. (2012). 3D subsidence analyses above gas reservoirs accounting for an unconventional plasticity model, Int. J. Numer. Anal. Methods Geomech., 36(8). DOI: 10.1002/nag.1032. 
[27] Tsutsumi, S., Toyosada, M., Hashiguchi, K. (2006). Extended Subloading Surface Model Incorporating Elastic Boundary Concept, J. Appl. Mech., 9, pp. 455-462. DOI: 10.2208/journalam.9.455.

[28] Chaboche, J.L. (1986). Time-independent constitutive theories for cyclic plasticity, Int. J. Plast., 2(2), pp. 149-188. DOI: $10.1016 / 0749-6419(86) 90010-0$.

[29] Rousselier, G., Luo, M. (2014). A fully coupled void damage and Mohr-Coulomb based ductile fracture model in the framework of a Reduced Texture Methodology, Int. J. Plast., 55, pp. 1-24. DOI: 10.1016/j.ijplas.2013.09.002.

[30] Fincato, R., Tsutsumi, S. (2018). Evaluation of the ductile fracture of Q460 steel under two different failure criteria, Procedia Struct. Integr., 9, pp. 126-135. DOI: 10.1016/j.prostr.2018.06.021.

[31] Rudnicki, J.W., Rice, J.R. (1975). Conditions for the localization of deformation in pressure-sensitive dilatant materials, J. Mech. Phys. Solids, 23(6), pp. 371-394. DOI: 10.1016/0022-5096(75)90001-0.

[32] Nishikawa, K., Yamamoto, S., Natori, T., Terao, K., Yasunami, H., Terada, M. (1998). Retrofitting for seismic upgrading of steel bridge columns, Eng. Struct., 20(4-6), pp. 540-551. DOI: 10.1016/S0141-0296(97)00025-4.

[33] Roscoe, K.H. (1970). The Influence of Strains in Soil Mechanics, Géotechnique, 20(2), pp. 129-170. DOI: 10.1680/geot.1970.20.2.129.

[34] Gao, S., Usami, T., Ge, H. (1998). Ductility Evaluation of Steel Bridge Piers with Pipe Sections, J. Eng. Mech., 124(3), pp. 260-267. DOI: 10.1061/(ASCE)0733-9399(1998)124:3(260).

[35] Ucak, A., Tsopelas, P. (2015). Load Path Effects in Circular Steel Columns under Bidirectional Lateral Cyclic Loading, J. Struct. Eng., 141(5), pp. 04014133, DOI: 10.1061/(ASCE)ST.1943-541X.0001057.

[36] Van Do, V.N., Lee, C.H., Chang, K.H. (2014). A nonlinear CDM model for ductile failure analysis of steel bridge columns under cyclic loading, Comput. Mech., 53(3), pp. 1209-1222. DOI: 10.1007/s00466-013-0964-2.

[37] Goto, Y., Kumar, G.P., Kawanishi, N. (2010). Nonlinear Finite-Element Analysis for Hysteretic Behavior of ThinWalled Circular Steel Columns with In-Filled Concrete, J. Struct. Eng., 136(11), pp. 1413-1422.

DOI: 10.1061/(ASCE)ST.1943-541X.0000240.

[38] De Freitas, M., Reis, L., Li, B. (2006). Comparative study on biaxial low-cycle fatigue behaviour of three structural steels, Fatigue Fract. Eng. Mater. Struct., 29(12), pp. 992-999. DOI: 10.1111/j.1460-2695.2006.01061.x.

\section{NOMENCLATURE}

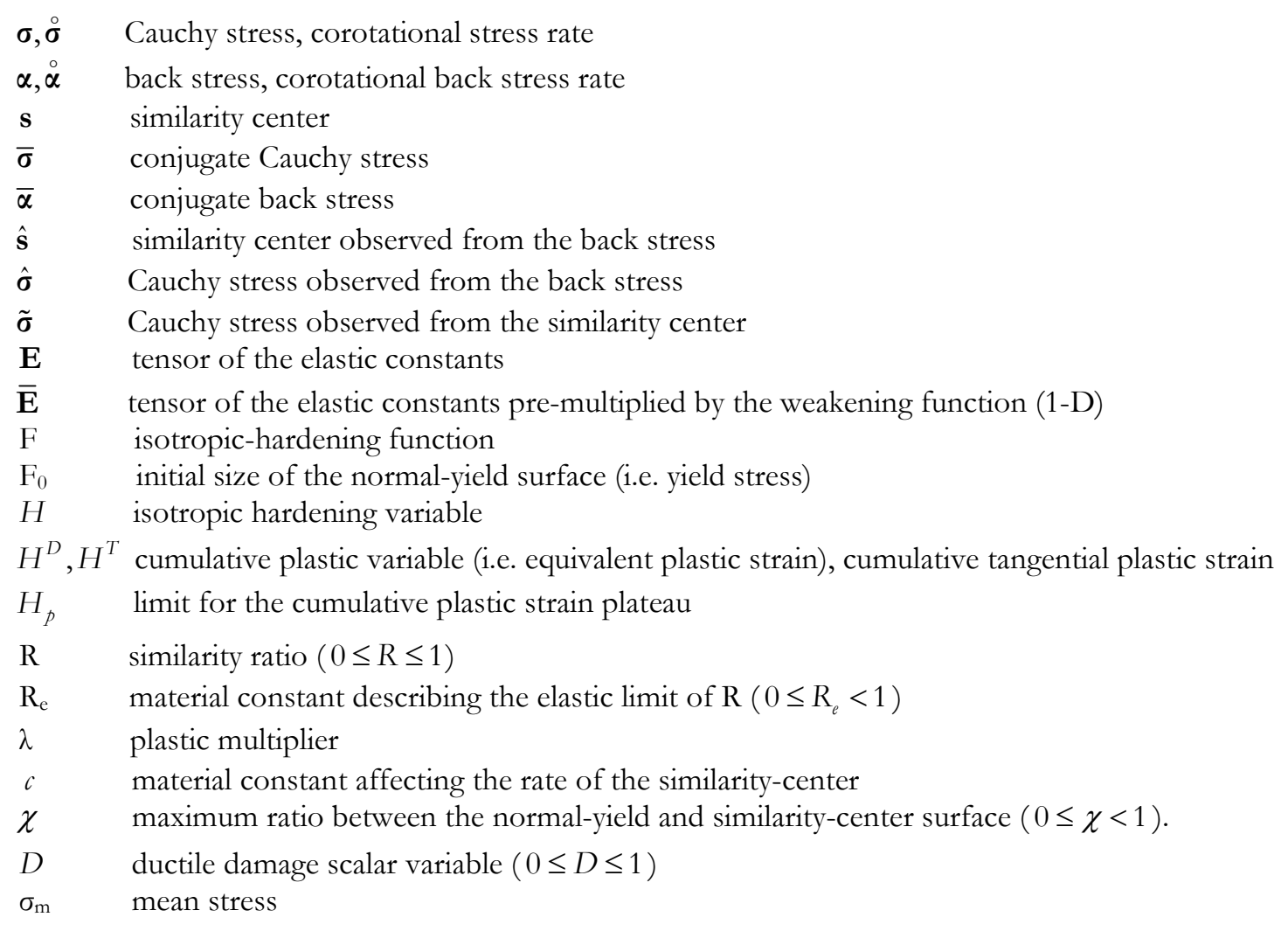


$\sigma_{\text {Mises }} \quad$ von Mises stress

$\eta \quad$ stress triaxiality

$\theta \quad$ Lode angle

$\bar{\theta} \quad$ Lode angle parameter $(-1<\bar{\theta}<1)$

$\bar{\varepsilon}_{f} \quad$ equivalent strain at fracture

$\langle a\rangle \quad$ McCauley's brackets: $\langle a\rangle=0$ if $a<0 ;\langle a\rangle=a$ if $a>0$

$\mathrm{H}[a-b]$ Heaviside step function: $\mathrm{H}[a-b]=0$ if $a-b<0 ; \quad \mathrm{H}[a-b]=1$ if $a-b>0$

$|\mathbf{A}| \quad$ norm of a generic second-order tensor $\boldsymbol{A},|\mathbf{A}|=\sqrt{\mathbf{A}: \mathbf{A}}$ 